\title{
A RARE CASE OF GENITAL POROKERATOSIS
}

\section{Dr. Sucheta Pathania*}

MD, Medical Officer(Dermatology, Venereology and leprosy) Zonal Hospital Dharamshala Himachal Pradesh, India. ${ }^{*}$ Corresponding Author

\section{ABSTRACT}

Porokeratosis is a keratinization disorder of unknownetiology. It is characterized by well defined annular plaques with central scarring or pigmentation and raised keratotic border. Disseminated superficial actinic porokeratosis, linear porokeratosis, porokeratosispalmaris et plantaris ,punctateporokeratosis are different clinical variants. Keratotic border is microscopically characterized by a column of parakeratotic cells invaginating the epidermis known as cornoid lamella which is a characteristic finding. Porokeratosis localized to the genital region is very rare. These lesions are mostly asymptomatic but there can be occasional pruritus. It mostly occurs on the scrotum followed by penis however adjoining areas like thighs, buttocks, natal cleft can also be involved. There are very few reports in Indian literature of porokeratsis limited to the genital region.

\section{KEYWORDS :}

\section{Case report:}

A 60 year old male presented with multiple slightly elevated lesions on the scrotal region for last 1 year. The lesions were asymptomatic. There was no bleeding, discharge or ulceration from the lesions. There was no other cutaneous or systemic complaints. Local examination revealed multiple variable sized hyperpigmented annular plaques with elevated borders distributed all over the scrotum. Histopathology from the border showed the presence of column of parakeratotic cells invaginating the epidermis (cornoid lamella). Routine laboratory examination like complete hemogram, liver and renal function tests were within normal limits. Based on clinical and histopathological findings a diagnosis of genital porokeratosis was made.

\section{DISCUSSION}

Porokeratosis is a disorder of keratinisation clinically characterized sharply demarcated and hyperkeratotic plaques with central atrophy and elevated borders. Mibelli in 1893 described the lesions of classcal porokeratosis. Disseminated superficial actinic porokeratosis (DSAP) was described by Cherosky in the year 1966. Porokeratosis of Mibelli, disseminated superficial porokeratosis, disseminated superficial actinic porokeratosis, porokeratosis palmaris et plantaris disseminate and punctate porokeratosis are the different clinical variants. Initially the lesions are small keratotic papules. They may be rythematous or pigmented. These gradually enlarge to form superficial ring like lesions with slight central atrophy and raised borders. ${ }^{1,2}$

Porokeratosis involving the genitalia can occur as part of generalized porokeratosis with genital involvement or as localized porokeratosis that is confined to the genital area. Genital porokeratosis is considered as an extremely rare entity. It is classified as classic or plaque-type porokeratosis of mibelli. Lesions of genital porokeratosis are usually asymptomatic, but there can be occasional pruritus. Scrotum is the commonly involved site, followed by penis. Adjacent areas like buttock, natal cleft, groins and thighs can also be involved. Very few cases of porokeratosis involving genitalia with or without involvement of adjacent areas have been reported in literature previously. ${ }^{3,4} \mathrm{Histopathology}$ is characterized by a column of parakeratotic cells invaginating the epidermis known as cornoid lamella. Decreased granular layer and dyskeratotic cells are often seen beneath the cornoid lamella. Treatment modalities for genital porokeratosis are same as that of porokeratosis occurring on any other site. These include cryotherapy (liquid $\mathrm{N}_{2}$ ), surgical excision, $\mathrm{CO}_{2}$ laser ablation, topical $5 \% 5$-fluorouracil, vit. D3 analogues, retinoids and imiquimod cream.
Figure 1: multiple hyperpigmented annular plaques with raised borders

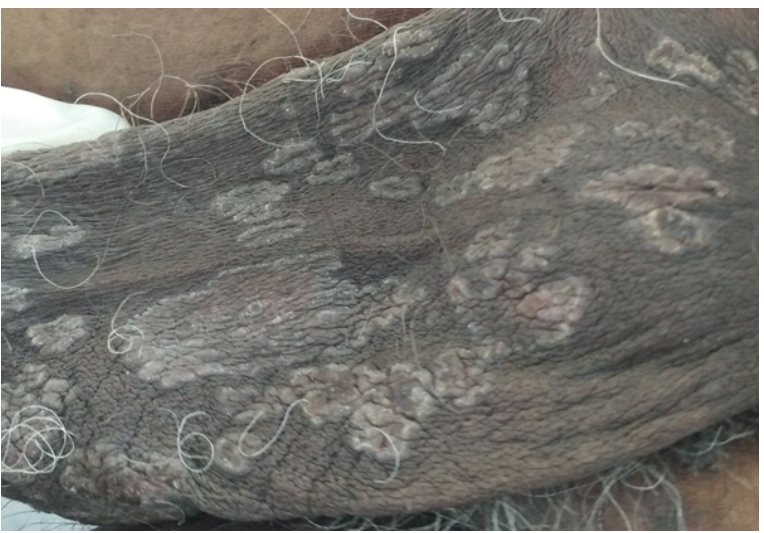

\section{REFERENCES}

1. Agarwal S, Berth Jones J. Porokeratosis of Mibelli. Br J Dermatol 2002; 14:338-9

2. Girgla HS, Bhattacharya SK: clinical study of porokeratosis: a report of 10 cases. Ind J Dermatol.1976;15:43

3. Sengupta S, Das JK, Gangopadhyay A. Porokeratosis confined to the genital area: A report of three cases. Indian J DermatolVenereolLeprol. 2008;7:80

4. Chen TJ, Chow YC, Chen CH, Kuo TT, Hong HS. Genital porokeratosis: A series of 10 patients and review of the literature. Br J Dermatol. 2006:155:325-9

Porter WM, Du P, Menagi H, Philip G, Bunker CB. Porokeratosis of the penis. Br J Dermatol. 2001;144:643-4 